\title{
Measuring medication adherence in patients with incident hypertension: a retrospective cohort study
}

\author{
Karen L. Tang ${ }^{1 *}$, Hude Quan ${ }^{2}$ and Doreen M. Rabi ${ }^{1,2}$
}

\begin{abstract}
Background: Though pharmacy claims data are commonly used to study medication adherence, there remains no standard operational definition for adherence especially for patients on multiple medications. Even when studies use the same terminology, the actual methods of calculating adherence can differ drastically. It is unclear whether the use of different definitions results in different conclusions regarding adherence and associated outcomes. The objective of our study was to compare adherence rates and associations with mortality using different operational definitions of adherence, and using various methods of handling concurrent medication use.

Methods: We conducted a cohort study of patients aged $\geq 65$ years from Manitoba, Canada, with incident hypertension diagnosed in 2004 and followed to 2009. We calculated adherence rates to anti-hypertensive medications using different operational definitions of medication adherence (including interval and prescription based medication possession ratios [MPR] and proportion of days covered [PDC]). For those on concurrent medications, we calculated adherence rates using the different methods of handling concurrent medication use, for each definition. We used logistic regression to determine the association between adherence and mortality for each operational definition.
\end{abstract}

Results: Among 2199 patients, $24.1 \%$ to $90.5 \%$ and $71.2 \%$ to $92.7 \%$ were considered adherent when using fixed interval and prescription-based interval medication possession ratios [MPRi and MPRp] respectively, depending on how concurrent medications were handled. Adherence was inversely associated with death, with the strongest association for MPRp measures. This association was significant only when considering adherence to any antihypertensive [aOR $0.70,95 \% \mathrm{Cl} 0.51,0.97$ ], or when the mean of the class-specific MPRp's [adjusted OR 0.71, 95\% Cl $0.53,0.95]$ was used. No significant association existed when the highest or lowest class-specific MPRp was used as the adherence estimate.

Conclusion: The range of adherence estimates varies widely depending on the operational definition used. Given less variation in adherence rates and their stronger association against mortality, we recommend using prescriptionbased MPR's to define medication adherence.

Keywords: Drug Utilization, Prescription Drugs, Adherence, Claims data, Hypertension

\footnotetext{
*Correspondence: klktang@ucalgary.ca

'Department of Medicine, University of Calgary, 3330 Hospital Drive NW, T2N

4N1 Calgary, Alberta, Canada

Full list of author information is available at the end of the article
} 


\section{Background}

Medication adherence is defined as the extent to which a patient takes prescribed medications according to the dosage and frequency recommended by the provider $[1,2]$. Non-adherence to prescribed medications is associated with poor treatment outcomes, increased hospitalizations, and increased cost to the health care system for chronic diseases such as hypertension, diabetes, and heart failure [3-5]. Despite the presence of a clinical definition of medication adherence, there remains no standard operational definition for medication adherence in health research, especially when using pharmacy claims data [6].

In the literature, there are a wide number of terms and operational definitions used to assess medication adherence (see Table 1 for a list of definitions used in the hypertension literature). Even when studies use the same terms, the operationalized or practical definition presented, the time frame considered, and the method of calculating adherence often differ. Most studies use the "medication possession ratio" (MPR) [1, 7] or similar related adherence measures, generally defined as the proportion of a time period where a medication supply is available [1]. Variations in MPR calculations stem from different denominators used, which can either be a fixed time interval or a variable period between prescriptions. The former is termed "interval based MPR" [MPRi] and the latter, "prescription based MPR" [MPRp] [8]. MPR can be reported as a continuous or as a dichotomized measure, where patients with an MPR above a certain threshold are considered "adherent". While the level of optimal adherence may differ for different clinical conditions, a threshold of 0.80 [1] is conventionally used.

Despite wide acceptance and usage of MPR, there remains significant variation not only in its specific calculation as mentioned above, but also in methods of managing multiple concurrent medications ("polytherapy") to obtain a single measure of adherence for each patient (see Table 2). Methods of calculating an MPR estimate for patients on polytherapy can consider either adherence to individual drug classes or adherence overall to any medication. In addition, a related measure to MPR termed Proportion of Days Covered [PDC] is often preferred in polytherapy due to its lower risk of overestimation [9]; PDC is defined as the proportion of days in a fixed observation period where at least one of multiple medications is available.

The many different operational definitions and methods used to handle polytherapy may result in very different adherence estimates and highly variable conclusions [8], highlighting the need to harmonize operational definitions of adherence used in health research. Our study objective was to compare adherence rates using the different operational definitions (MPRi, MPRp, and PDC) and methods of handling concurrent medications, and to determine the strengths of association between medication adherence using these different operational definitions with all-cause mortality in a population of Canadians with newly diagnosed hypertension.

\section{Methods}

\section{Sources of data}

Administrative data extracted from hospital discharge abstracts and physician claims were collected in Manitoba, Canada from April 1, 1997 to March 31, 2009. We linked this database with vital statistics for mortality data, the health insurance registry for demographic data, and the Manitoba Pharmacare prescription database for drug data. Drug data from April 1, 2002 to March 31, 2009 were used for this study. Given the universality of Manitoba Pharmacare, this database contains dispensing records for all outpatient prescription drug claims for all Manitoban residents, with the exception of First Nations and Inuit persons, inmates incarcerated in federal penitentiaries, military personnel, RCMP, and veterans; these subgroups are covered by the federal drug benefit plan [10]. Institutional ethics board approval was obtained from the University of Calgary Conjoint Health Research Ethics Board. Manitoba Health granted access to the administrative databases used in this study. Direct patient consent was not obtained, as the data being analyzed were routinely collected administrative health data that had been de-identified prior to receipt of data.

\section{Study population}

The 25 diagnosis fields in hospital discharge abstracts and the 1 field in physician claims were searched for the relevant International Classification of Diseases, Ninth and Tenth Revisions (ICD-9 and ICD-10) codes for hypertension (401.x-405.x, 110.x-115.x). The case definition for incident hypertension in the databases was one hospitalization or two physician claims within 2 years with a hypertension ICD code. We determined incidence with a three-year washout period [11]. Index date of diagnosis was the first date at which the case definition was fulfilled. Patients without at least a single prescription refill within one year after the first prescription fill in any of the five antihypertensive medication classes of interest (thiazide-type diuretics, beta blockers [BB], calcium channel blockers [CCB], angiotensin converting enzyme inhibitors or angiotensin receptor blockers [ACEI/ARB], or a combination containing at least one of the above classes; see Appendix 1), and patients who died within one year of the first prescription fill were excluded to ensure that each operational definition could be calculated for each patient. The study population included a random sample of Manitoba residents aged $\geq 65$ years with incident hypertension, with an index date of diagnosis between April 1, 2004 and March 31, 2005. 


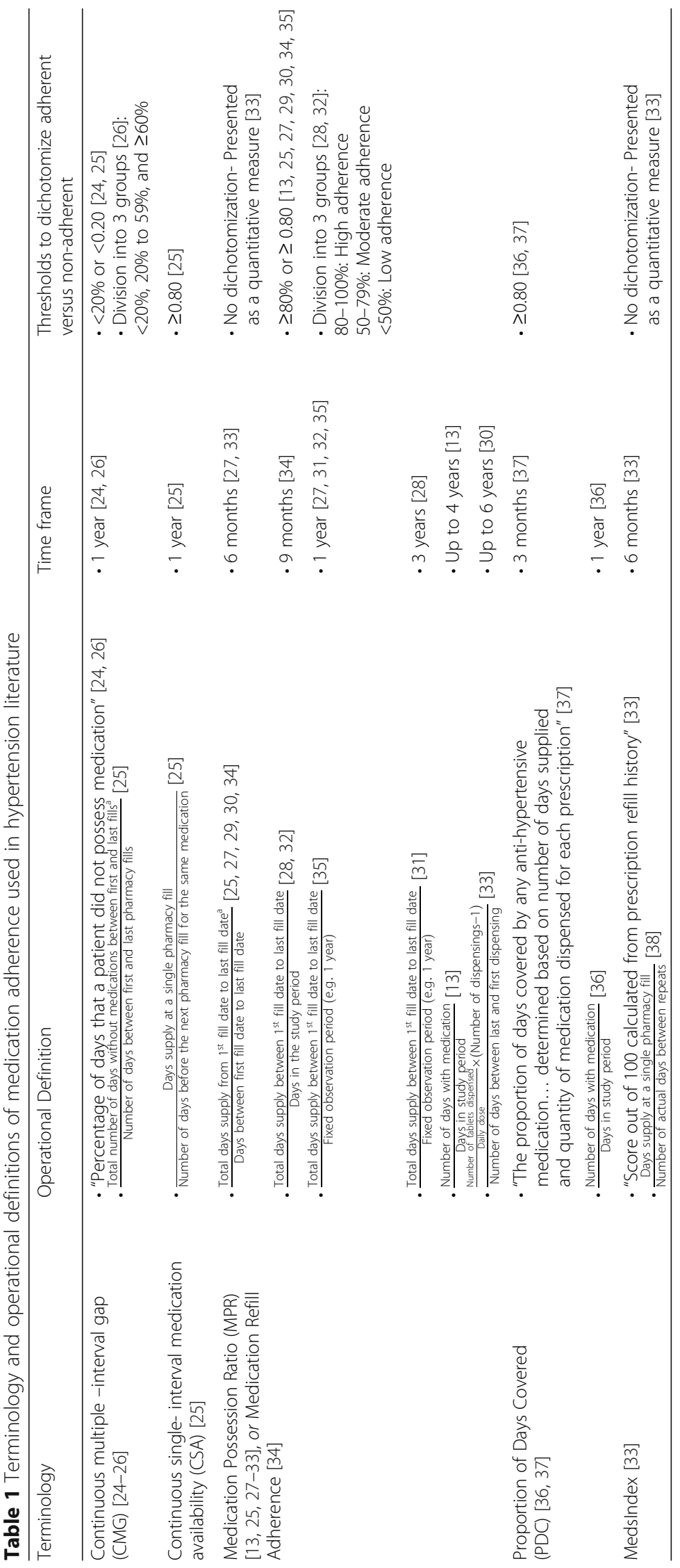


Table 2 Methods of handling use of multiple concurrent anti-hypertensive medications when measuring adherence in hypertension literature

\begin{tabular}{|c|c|c|}
\hline Measure & Method of handling concurrent medications & $\begin{array}{l}\text { Method considers adherence to } \\
\text { any medication versus adherence } \\
\text { to each medication }\end{array}$ \\
\hline \multirow[t]{3}{*}{ CMG [24-26] } & $\begin{array}{l}\text { Sum of the total number of gap days (days the } \\
\text { patient did not possess the medication) for each } \\
\text { anti-hypertensive medication divided by the sum } \\
\text { of the total number of days the patient was } \\
\text { prescribed each anti-hypertensive medication }[24,26]\end{array}$ & Any \\
\hline & $\begin{array}{l}\text { Calculate and report CMG for each } \\
\text { anti-hypertensive medication class [26] }\end{array}$ & Each \\
\hline & $\begin{array}{l}\text { Calculate CMG for each anti-hypertensive } \\
\text { medication class, then take the mean } \\
\text { CMG for each patient [25] }\end{array}$ & Each \\
\hline CSA [25] & $\begin{array}{l}\text { Calculate CSA for each anti-hypertensive } \\
\text { medication class, then take the mean CSA } \\
\text { for each patient [25] }\end{array}$ & Each \\
\hline \multirow[t]{9}{*}{ MPR $[13,25,27-35][39]$} & Exclude patients not on monotherapy [28] & N/A \\
\hline & Method of handling polytherapy not reported [33] & N/A \\
\hline & $\begin{array}{l}\text { Calculate and report for each class of } \\
\text { anti-hypertensive medication }[27,30]\end{array}$ & Each \\
\hline & $\begin{array}{l}\text { Take the single medication with the maximum } \\
\text { number of days supply over one year period } \\
\text { and use this single medication for the MPR } \\
\text { estimate for the patient [35] }\end{array}$ & Each \\
\hline & $\begin{array}{l}\text { Calculate MPR for each anti-hypertensive } \\
\text { mediation class, then take the lowest MPR } \\
\text { (for the medication with lowest adherence) } \\
\text { as the MPR estimate for each patient }[34,39]\end{array}$ & Each \\
\hline & $\begin{array}{l}\text { Calculate MPR for each anti-hypertensive } \\
\text { medication class, then take the mean MPR } \\
\text { for each patient }[25,29,32,34]\end{array}$ & Each \\
\hline & $\begin{array}{l}\text { Include all days where at least one anti-hypertensive } \\
\text { medication was available in the numerator of the } \\
\text { ratio of number of days with medication to days } \\
\text { in study period [13] }\end{array}$ & Any \\
\hline & $\begin{array}{l}\text { Calculate numerator for MPR by taking sum of all } \\
\text { days supply of all anti-hypertensive medications } \\
\text { prescribed as the numerator [40] }\end{array}$ & Any \\
\hline & $\begin{array}{l}\text { Include only days where all anti-hypertensive } \\
\text { medications of interest were available [31] }\end{array}$ & Each \\
\hline $\operatorname{PDC}[36,37]$ & $\begin{array}{l}\text { Include all days where at least one anti-hypertensive } \\
\text { medication was available in the numerator of the } \\
\text { ratio of number of days with medication to days } \\
\text { in study period }[36,37]\end{array}$ & Any \\
\hline MedsIndex [33] & Method of handling polytherapy not reported [33] & N/A \\
\hline
\end{tabular}

Abbreviations: CMG Continuous multiple-interval gap, CSA Continuous single-interval medication availability, MPR Medication possession ratio, PDC proportion of days covered, N/A Not applicable

\section{Sample size calculation}

Using conservative assumptions, the target sample size, assuming that the mortality rate of patients over the age of 65 years old with hypertension who are non-adherent to medications is $17 \%$ [12], to achieve a power of $80 \%$, a level of significance of $5 \%$, and to detect a relative risk ratio of mortality of 0.72 [13] for patients who are adherent to medications compared with patients who are non-adherent to medications, is 2124. To account for the exclusion of approximately $30 \%$ of the entire sample either because they have not had had a single fill or refill of any anti-hypertensive medications in the entire follow-up period, or die within the first year of diagnosis, 3000 patients with incident hypertension were 
randomly selected for analysis. Random sampling was performed using the probability proportional to size method based on age, sex, and comorbidities.

\section{Measures of medication adherence}

We calculated MPR using the following 2 formulae (interval-based and prescription-based MPR respectively) for an observation period of 1 year:

$$
\mathrm{MPRi}=\frac{\text { Days supply of medication }}{365 \text { days }}, \text { capped at } 1
$$

MPRp

$=\frac{\text { Days supply of medication excluding supply from last refill }}{\text { Last refill date-First refill date }}$, capped at 1

Medications within the same medication class (Appendix 1) were considered interchangeable.

For patients on polytherapy in our study, we calculated four different MPRi's and MPRp's: a) MPR considering adherence to any antihypertensive, obtained by first summing the days supply of each anti-hypertensive prescription in the numerator [9], then dividing by the denominator as stated above; b) average of the MPR's specific to each anti-hypertensive medication class $[8,14]$; c) calculating the MPR's specific to each medication class, then taking the highest of the class-specific MPR's [15]; and d) calculating the MPR's specific to each medication class, then taking the lowest of the class-specific MPR's [16]. We termed these methods "sum MPR", "mean MPR", "high MPR" and "low MPR" respectively. Of note, for sum MPR, no medication class-specific MPRs are calculated. The denominator used for sum MPRp is the last refill date for any of the medication classes minus the first refill date for any of the medication classes (even if this medication class is not the same one used for the last refill date). We also calculated PDC for each patient by dividing the number of days where at least one medication was available (each day is considered individually and is a binary measure) [9] by 365 days.

MPR's and PDC's were additionally dichotomized using the standard threshold of 0.80 . For patients on anti-hypertensive therapy prior to the index date, adherence measures were calculated from the first prescription fill starting from 2002. If prescription refills were obtained prior to exhaustion of the supply of the previous fill for the same medication class, the date of the refill was prorated to start on the day after exhaustion of the previous supply.

\section{Mortality}

The primary outcome measure was mortality from the period 2005 to 2009 (a maximum of 5 years of followup). Any patients moving out-of-province or reaching the end of the observation period were censored.

\section{Statistical analysis}

Means and medians for continuous medication adherence variables were reported. These variables were also dichotomized, and Fisher's exact test was used to compare the proportion of adherent and nonadherent patients who had died. We also stratified this analysis by age, sex, income, and number of comorbidities. Multiple logistic regression models were employed to model the odds of death for those who are adherent to medications, compared to those who were non-adherent to medications, using the different operational definitions for adherence. The threshold used to define adherence was an MPR or PDC $\geq 0.80$. Unadjusted and adjusted Cox proportional hazards regressions were performed for each operational definition of adherence, to assess time to death. Given their potential to confound the association between medication adherence and mortality, we controlled for demographic and comorbidity variables in our adjusted logistic regression and Cox proportional hazards regression models; these variables included age, sex, Charlson comorbidity index, income quintile, and previous hospitalization for cardiovascular disease within three years prior to the index date of hypertension diagnosis. Data on health-related behaviours, such as diet and activity levels, were not available given the nature of data used in this study and thus no adjustment for these variables were undertaken. However, previous studies have shown weak correlations and non-statistically significant associations between health-related behaviours and medication adherence [17-20]. Health-related behaviours are therefore unlikely to be a significant confounder in the associations between medication adherence and mortality. All analyses were conducted using SAS Version 9.4 (SAS Institute, Cary, NC).

\section{Sensitivity analysis}

Because there is no robust evidence base to suggest that an MPR or PDC threshold of 0.80 used to classify those who are adherent versus non-adherent to medications is optimal or superior to other thresholds, we conducted sensitivity analysis, using various other adherence thresholds. For this sensitivity analysis, adjusted logistic regression as described above was also performed for thresholds of $0.70,0.75,0.85$, and 0.90 , for each of the operational definitions studied.

\section{Results}

Baseline characteristics

From a total of 5189 eligible patients aged 65 years or older with incident hypertension diagnosed in the 2004 fiscal year, a random sample of 3000 patients 
were selected for analysis. Of this sample of 3000 patients, we excluded those with no prescription filled for any anti-hypertensive in the entire follow-up period $(n=652)$, those who died within one year of their first anti-hypertensive prescription fill $(n=51)$, and those without at least one medication refill within one year of their first prescription fill $(n=98)$. Our final cohort comprised of 2199 patients. The median and mean follow-up durations were 4.41 years (interquartile range $4.11,4.72$ ) and 4.13 years (standard deviation 0.99) respectively.

Baseline characteristics can be found in Table 3. Overall, mean (SD) age was 75.2 (7.0) years, $45.4 \%$ were male, $12.2 \%$ had a previous hospitalization for cardiovascular disease, $33.7 \%$ were new users of anti-hypertensives, and $64.7 \%$ were on monotherapy. Comparison of baseline characteristics between non-adherent and adherent groups depended on the adherence measure being used (Table 3).

\section{Adherence rates by operational definition}

For patients on monotherapy $(n=1422)$, MPRi adherence estimates (mean 0.83, SD 0.23) were similar though consistently lower than the equivalent MPRp estimates (mean 0.87, SD 0.19, see Table 4). The PDC and MPRi methods gave identical adherence estimates for those on monotherapy only. These findings were consistent even with stratification by age, sex, income, and comorbidities.

In polytherapy $(n=777)$, the range of adherence rates varied widely, based on whether MPRi or MPRp was used, and also depending on the method used to manage polytherapy (Table 5). The lowest overall estimate of adherence was with using the "low MPRi" method, or taking the lowest class-specific MPRi for each patient (mean 0.47, SD 0.32). The highest overall estimate of adherence was with using the "sum MPRi" method, or by taking the sum of the days supply from each antihypertensive medication class as the numerator in the calculation of MPRi (mean 0.95, SD 0.13). "Mean MPRi" (0.66, SD 0.23) and "high MPRi" (0.84, SD 0.21) resulted in adherence estimates between these two extremes. Similarly, when adherence measures were dichotomized, the proportion of adherent users ranged from 24.1\% with "low MPRi" to $90.5 \%$ with "sum MPRi". In contrast to patients on monotherapy, PDC and MPRi (regardless of the method used to handle polytherapy) do not give the same adherence estimates for patients on polytherapy.

The range of adherence was much narrower for MPRp adherence estimates, with "low MPRp" giving again the lowest adherence estimate (mean 0.84, SD 0.21 ) and "sum MPRp" giving the highest estimate (mean 0.96, SD 0.12). The variation in the proportion of adherent users was also much smaller using MPRp, ranging from $71.2 \%$ with "low MPRp" to $92.7 \%$ with "sum MPRp". PDC gave a more conservative measure compared to both sum MPRi and sum MPRp; 83.0\% of the sample was classified as adherent using PDC. Even with stratification across age, sex, income, and comorbidities, the same patterns could be seen where MPRi's gave much wider ranges of adherence estimates compared with MPRp's, with "low MPR" giving the lowest estimates and "sum MPR" giving the highest estimates regardless of whether the prescription or interval based MPR method was used.

\section{Association between adherence and mortality}

A total of $387(17.6 \%)$ deaths occurred in the followup period. Greater medication adherence was consistently associated with lower odds of death, after risk adjustment (see Table 6). Overall, the strength of association was stronger for MPRp than for MPRi or PDC (adjusted odds ratio [aOR] for "sum MPRp" was 0.70 [95\% CI 0.51, 0.97] for "sum MPRi" aOR 0.78 [95\% CI 0.58, 1.05], for PDC aOR 0.80 [95\% CI 0.60, 1.07]). Of the numerous methods of handling concurrent medication use, "sum MPRp" and "mean MPRp" had the strongest associations with mortality with these being the only measures to reach statistical significance (aOR $0.70 \quad\left[\begin{array}{llll}95 \% & C I & 0.51, & 0.97\end{array}\right]$ and 0.71 [95\% CI 0.53, 0.95] respectively).

Similarly, in monotherapy, the association between medication adherence and mortality was stronger for MPRp measures than for MPRi and PDC measures based on point estimates, despite none reaching statistical significance. In polytherapy patients, the same inverse association could be seen between medication adherence as measured by MPRp and death, with the strongest associations seen again with "sum" and "mean" MPRp, though again none reached statistical significance.

Unadjusted and adjusted Cox proportional hazards regression provided similar results to logistic regression. However, testing of the proportional hazards assumption indicated its violation. Kaplan-Meier survival curves revealed a divergence of survival in adherent versus nonadherent groups at approximately 3.5 to 4 years post index date of hypertension diagnosis for MPRp definitions (with a less prominent trend using MPRi and PDC definitions).

\section{Sensitivity analysis}

Similar results were seen when adjusted logistic regression was performed using different adherence thresholds for each of the operational definitions (Appendix 2). Across all adherence thresholds, adherence estimates as measured by MPRp were more strongly associated with 


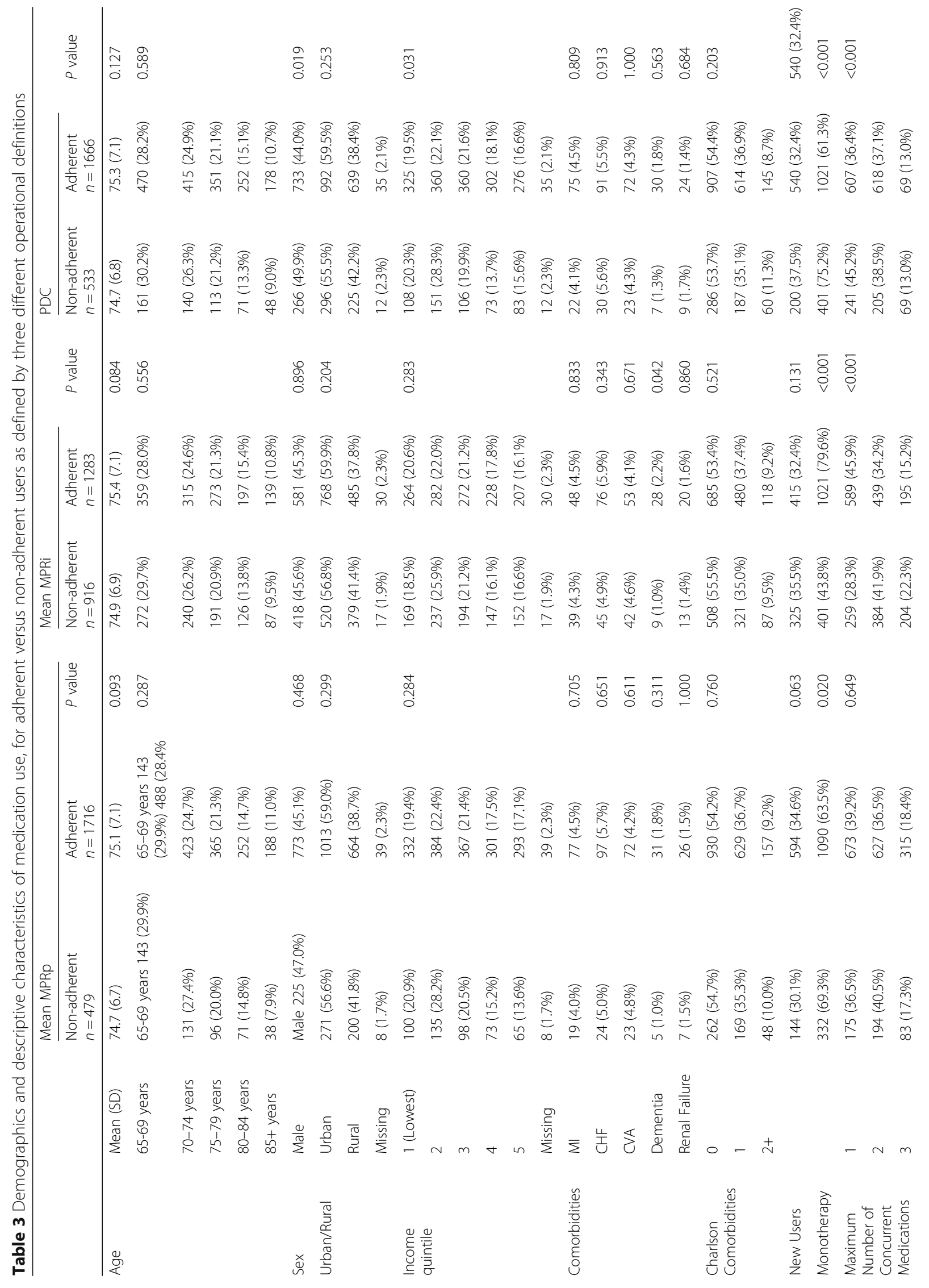




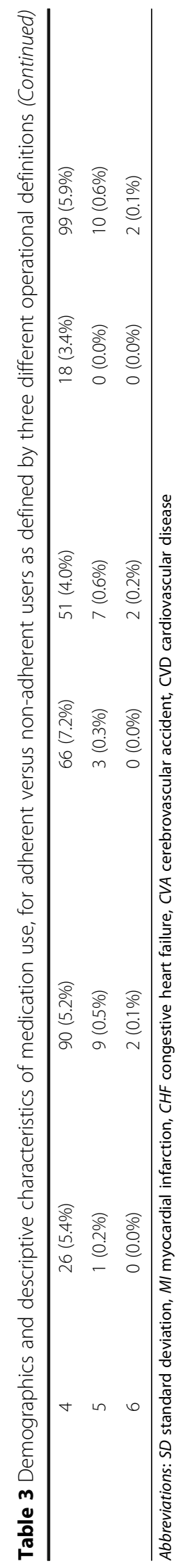


Table 4 Mean and median adherence rates, and proportion with adherence $\geq 0.80$ for patients on monotherapy $(n=1422)$

\begin{tabular}{|c|c|c|c|c|c|c|}
\hline & & & Range & Mean (SD) & Median (IQR) & Proportion $\geq 0.80$ \\
\hline \multirow[t]{3}{*}{ Overall } & & MPRi & $0.04-1.00$ & $0.83(0.23)$ & $0.95(0.75,0.99)$ & $71.8 \%$ \\
\hline & & MPRp & $0.04-1.00$ & $0.87(0.19)$ & $0.96(0.82,1.00)$ & $76.7 \%$ \\
\hline & & PDC & $0.08-1.00$ & $0.82(0.23)$ & $0.93(0.72,0.99)$ & $67.9 \%$ \\
\hline \multirow[t]{6}{*}{ Age } & 65 to 74 years & MPRi & $0.08-1.00$ & $0.82(0.23)$ & $0.93(0.72,0.99)$ & $67.9 \%$ \\
\hline & & MPRp & $0.09-1.00$ & $0.85(0.21)$ & $0.95(0.78,1.00)$ & $73.6 \%$ \\
\hline & & PDC & $0.08-1.00$ & $0.82(0.23)$ & $0.93(0.72,0.99)$ & $67.9 \%$ \\
\hline & 75 years and over & MPRi & $0.04-1.00$ & $0.84(0.22)$ & $0.95(0.77,0.99)$ & $73.4 \%$ \\
\hline & & MPRp & $0.04-1.00$ & $0.87(0.19)$ & $0.96(0.83,1.00)$ & $77.9 \%$ \\
\hline & & PDC & $0.04-1.00$ & $0.84(0.22)$ & $0.95(0.77,0.99)$ & $73.4 \%$ \\
\hline \multirow[t]{6}{*}{ Sex } & Male & MPRi & $0.04-1.00$ & $0.82(0.23)$ & $0.94(0.73,0.99)$ & $67.9 \%$ \\
\hline & & MPRp & $0.04-1.00$ & $0.85(0.21)$ & $0.95(0.80,1.00)$ & $73.6 \%$ \\
\hline & & PDC & $0.04-1.00$ & $0.82(0.23)$ & $0.94(0.73,0.99)$ & $67.9 \%$ \\
\hline & Female & MPRi & $0.10-1.00$ & $0.84(0.22)$ & $0.96(0.78,0.99)$ & $73.4 \%$ \\
\hline & & MPRp & $0.08-1.00$ & $0.87(0.19)$ & $0.96(0.82,1.00)$ & $77.9 \%$ \\
\hline & & PDC & $0.10-1.00$ & $0.84(0.22)$ & $0.96(0.78,0.99)$ & $73.4 \%$ \\
\hline \multirow[t]{4}{*}{ Income } & Lowest quintile & MPRi & $0.05-1.00$ & $0.83(0.24)$ & $0.95(0.77,0.99)$ & $73.1 \%$ \\
\hline & & MPRp & $0.04-1.00$ & $0.87(0.20)$ & $0.96(0.83,1.00)$ & $77.9 \%$ \\
\hline & & PDC & $0.05-1.00$ & $0.83(0.24)$ & $0.95(0.77,0.99)$ & $73.1 \%$ \\
\hline & Highest quintile & MPRi & $0.10-1.00$ & $0.85(0.20)$ & $0.95(0.74,0.99)$ & $71.7 \%$ \\
\hline \multirow{6}{*}{$\begin{array}{l}\text { Charlson } \\
\text { comorbidities }\end{array}$} & 0 or 1 comorbidities & MPRi & $0.04-1.00$ & $0.84(0.22)$ & $0.95(0.76,0.99)$ & $72.6 \%$ \\
\hline & & MPRp & $0.08-1.00$ & $0.87(0.19)$ & $0.96(0.82,1.00)$ & $77.2 \%$ \\
\hline & & PDC & $0.04-1.00$ & $0.84(0.22)$ & $0.95(0.76,0.99)$ & $72.6 \%$ \\
\hline & $2+$ comorbidities & MPRi & $0.05-1.00$ & $0.79(0.26)$ & $0.92(0.61,1.00)$ & $63.9 \%$ \\
\hline & & MPRp & $0.04-1.00$ & $0.83(0.23)$ & $0.94(0.77,1.00)$ & $71.5 \%$ \\
\hline & & PDC & $0.05-1.00$ & $0.79(0.26)$ & $0.92(0.61,1.00)$ & $63.9 \%$ \\
\hline
\end{tabular}

Abbreviations: $S D$ standard deviation, IQR interquartile range, MPRi interval based medication possession ratio, MPRp prescription based medication possession ratio, $P D C$ proportion of days covered

mortality than as measured by MPRi. The MPRp definitions that showed a statistically significant association between adherence and mortality varied depending on the adherence threshold used. Statistical significance for this association was reached for mean MPRp when using adherence thresholds of $0.70,0.75$, and 0.80 ; for sum MPRp, the adherence thresholds were 0.80 and 0.85 . For low MPRp, statistical significance was reached when the adherence threshold used was 0.70 .

\section{Discussion}

In a cohort of 2199 patients with incident hypertension, we found that different definitions of medication adherence resulted not only in different baseline characteristics of "adherent" and "non-adherent" groups but also vast differences in estimated adherence rates. Similar to previous studies, adherence measures based on a fixed observation period (MPRi and PDC) resulted in lower adherence estimates compared with variable observation periods based on prescription refill dates (MPRp) [8, 21]. In addition, different methods of calculating adherence for patients on polytherapy provided very different estimates of adherence [8]. For example, if only those with an MPRi of $\geq 0.80$ for each and every medication class were considered adherent, only $24.1 \%$ would be classified as being adherent. Conversely, if we considered those with an overall MPRi of $\geq 0.80$, when all medication classes were grouped together, as adherent, over 90\% of the same sample population would be classified as adherent. Therefore, given this wide variation in adherence estimates and their implications on study conclusions, it is imperative that future adherence studies are transparent in providing information regarding: 1) specific operational definitions of adherence used and the numerator and denominator used in these calculations; and 2) the method used to manage polytherapy. Because adherence measure names 
Table 5 Mean and median adherence rates and proportion with adherence $\geq 0.80$ for patients on polytherapy $(n=777)$

\begin{tabular}{|c|c|c|c|c|c|c|c|}
\hline & & & & Range & Mean (SD) & Median (IQR) & Proportion $\geq 0.80$ \\
\hline \multirow[t]{9}{*}{ Overall } & & MPRi & Low & $0.01-1.00$ & $0.47(0.32)$ & $0.41(0.16,0.77)$ & $24.1 \%$ \\
\hline & & & High & $0.15-1.00$ & $0.84(0.21)$ & $0.93(0.74,0.99)$ & $69.6 \%$ \\
\hline & & & Sum & $0.25-1.00$ & $0.95(0.13)$ & $1.00(1.00,1.00)$ & $90.5 \%$ \\
\hline & & & Mean & $0.11-1.00$ & $0.66(0.23)$ & $0.64(0.49,0.87)$ & $33.7 \%$ \\
\hline & & MPRp & Low & $0.05-1.00$ & $0.84(0.21)$ & $0.92(0.77,0.99)$ & $71.2 \%$ \\
\hline & & & High & $0.10-1.00$ & $0.94(0.13)$ & $1.00(0.94,1.00)$ & $89.5 \%$ \\
\hline & & & Sum & $0.16-1.00$ & $0.96(0.12)$ & $1.00(1.00,1.00)$ & $92.7 \%$ \\
\hline & & & Mean & $0.10-1.00$ & $0.89(0.15)$ & $0.95(0.84,0.99)$ & $81.0 \%$ \\
\hline & & PDC & & $0.15-1.00$ & $0.90(0.18)$ & $0.98(0.90,1.00)$ & $83.0 \%$ \\
\hline \multirow[t]{18}{*}{ Age } & 65 to 74 years & MPRi & Low & $0.01-1.00$ & $0.50(0.32)$ & $0.48(0.19,0.82)$ & $25.2 \%$ \\
\hline & & & High & $0.16-1.00$ & $0.85(0.19)$ & $0.92(0.79,0.99)$ & $73.5 \%$ \\
\hline & & & Sum & $0.33-1.00$ & $0.97(0.11)$ & $1.00(1.00,1.00)$ & $93.2 \%$ \\
\hline & & & Mean & $0.11-1.00$ & $0.67(0.23)$ & $0.69(0.49,0.88)$ & $37.2 \%$ \\
\hline & & MPRp & Low & $0.05-1.00$ & $0.83(0.22)$ & $0.91(0.78,0.98)$ & $71.8 \%$ \\
\hline & & & High & $0.10-1.00$ & $0.93(0.15)$ & $1.00(0.94,1.00)$ & $89.7 \%$ \\
\hline & & & Sum & $0.20-1.00$ & $0.96(0.12)$ & $1.00(1.00,1.00)$ & $92.7 \%$ \\
\hline & & & Mean & $0.10-1.00$ & $0.88(0.17)$ & $0.94(0.84,0.99)$ & $82.5 \%$ \\
\hline & & PDC & & $0.16-1.00$ & $0.91(0.16)$ & $0.98(0.91,1.00)$ & $85.9 \%$ \\
\hline & 75 years and over & MPRi & Low & $0.01-1.00$ & $0.46(0.33)$ & $0.39(0.16,0.76)$ & $23.6 \%$ \\
\hline & & & High & $0.15-1.00$ & $0.83(0.21)$ & $0.94(0.74,0.99)$ & $68.0 \%$ \\
\hline & & & Sum & $0.25-1.00$ & $0.95(0.14)$ & $1.00(1.00,1.00)$ & $89.3 \%$ \\
\hline & & & Mean & $0.11-1.00$ & $0.65(0.23)$ & $0.63(0.48,0.87)$ & $32.2 \%$ \\
\hline & & MPRp & Low & $0.08-1.00$ & $0.84(0.21)$ & $0.93(0.77,0.99)$ & $70.9 \%$ \\
\hline & & & High & $0.20-1.00$ & $0.94(0.12)$ & $1.00(0.94,1.00)$ & $89.4 \%$ \\
\hline & & & Sum & $0.16-1.00$ & $0.96(0.11)$ & $1.00(1.00,1.00)$ & $92.6 \%$ \\
\hline & & & Mean & $0.15-1.00$ & $0.89(0.15)$ & $0.96(0.85,0.99)$ & $80.3 \%$ \\
\hline & & PDC & & $0.15-1.00$ & $0.89(0.19)$ & $0.99(0.88,1.00)$ & $81.8 \%$ \\
\hline \multirow[t]{17}{*}{ Sex } & Male & MPRi & Low & $0.01-1.00$ & $0.50(0.33)$ & $0.44(0.16,0.82)$ & $26.2 \%$ \\
\hline & & & High & $0.15-1.00$ & $0.83(0.22)$ & $0.93(0.74,0.99)$ & $69.2 \%$ \\
\hline & & & Sum & $0.25-1.00$ & $0.94(0.15)$ & $1.00(1.00,1.00)$ & $89.1 \%$ \\
\hline & & & Mean & $0.11-1.00$ & $0.66(0.24)$ & $0.67(0.48,0.88)$ & $36.6 \%$ \\
\hline & & MPRp & Low & $0.05-1.00$ & $0.83(0.22)$ & $0.92(0.78,0.98)$ & $70.5 \%$ \\
\hline & & & High & $0.18-1.00$ & $0.93(0.14)$ & $0.99(0.93,1.0)$ & $90.8 \%$ \\
\hline & & & Sum & $0.16-1.00$ & $0.96(0.13)$ & $1.00(1.00,1.00)$ & $91.9 \%$ \\
\hline & & & Mean & $0.15-1.00$ & $0.88(0.16)$ & $0.95(0.84,0.99)$ & $80.9 \%$ \\
\hline & & PDC & & $0.15-1.00$ & $0.88(0.20)$ & $0.98(0.85,1.00)$ & $80.4 \%$ \\
\hline & Female & MPRi & Low & $0.01-1.00$ & $0.45(0.32)$ & $0.38(0.16,0.74)$ & $22.3 \%$ \\
\hline & & & High & $0.16-1.00$ & $0.84(0.19)$ & $0.94(0.75,0.99)$ & $70.0 \%$ \\
\hline & & & Sum & $0.33-1.00$ & $0.96(0.12)$ & $1.00(1.00,1.00)$ & $91.6 \%$ \\
\hline & & & Mean & $0.11-1.00$ & $0.65(0.22)$ & $0.63(0.49,0.86)$ & $31.4 \%$ \\
\hline & & MPRp & Low & $0.10-1.00$ & $0.84(0.20)$ & $0.93(0.77,0.99)$ & $71.7 \%$ \\
\hline & & & High & $0.10-1.00$ & $0.94(0.13)$ & $1.00(0.95,1.00)$ & $88.5 \%$ \\
\hline & & & Sum & $0.20-1.00$ & $0.97(0.10)$ & $1.00(1.00,1.00)$ & $93.3 \%$ \\
\hline & & & Mean & $0.10-1.00$ & $0.89(0.15)$ & $0.95(0.85,0.99)$ & $81.0 \%$ \\
\hline
\end{tabular}


Table 5 Mean and median adherence rates and proportion with adherence $\geq 0.80$ for patients on polytherapy $(n=777)$ (Continued)

\begin{tabular}{|c|c|c|c|c|c|c|c|}
\hline & & PDC & & $0.16-1.00$ & $0.91(0.16)$ & $0.99(0.91,1.00)$ & $85.1 \%$ \\
\hline \multirow[t]{18}{*}{ Income } & \multirow[t]{9}{*}{ Lowest quintile } & \multirow[t]{4}{*}{ MPRi } & Low & $0.01-1.00$ & $0.47(0.31)$ & $0.42(0.16,0.75)$ & $20.1 \%$ \\
\hline & & & High & $0.16-1.00$ & $0.83(0.21)$ & $0.93(0.74,0.99)$ & $66.9 \%$ \\
\hline & & & Sum & $0.33-1.00$ & $0.95(0.14)$ & $1.00(1.00,1.00)$ & $90.7 \%$ \\
\hline & & & Mean & $0.11-1.00$ & $0.65(0.23)$ & $0.63(0.46,0.86)$ & $35.3 \%$ \\
\hline & & \multirow[t]{4}{*}{ MPRp } & Low & $0.10-1.00$ & $0.79(0.24)$ & $0.89(0.68,0.99)$ & $61.6 \%$ \\
\hline & & & High & $0.10-1.00$ & $0.92(0.16)$ & $1.00(0.91,1.00)$ & $85.5 \%$ \\
\hline & & & Sum & $0.16-1.00$ & $0.94(0.15)$ & $1.00(1.00,1.00)$ & $88.5 \%$ \\
\hline & & & Mean & $0.10-1.00$ & $0.86(0.18)$ & $0.92(0.80,0.99)$ & $74.6 \%$ \\
\hline & & PDC & & $0.16-1.00$ & $0.88(0.19)$ & $0.98(0.84,1.00)$ & $79.1 \%$ \\
\hline & \multirow[t]{9}{*}{ Highest quintile } & \multirow[t]{4}{*}{ MPRi } & Low & $0.01-1.00$ & $0.47(0.32)$ & $0.40(0.16,0.79)$ & $24.6 \%$ \\
\hline & & & High & $0.19-1.00$ & $0.83(0.20)$ & $0.93(0.69,0.99)$ & $67.5 \%$ \\
\hline & & & Sum & $0.36-1.00$ & $0.95(0.12)$ & $1.00(1.00,1.00)$ & $90.5 \%$ \\
\hline & & & Mean & $0.12-1.00$ & $0.65(0.23)$ & $0.63(0.49,0.88)$ & $31.8 \%$ \\
\hline & & \multirow[t]{4}{*}{ MPRp } & Low & $0.14-1.00$ & $0.87(0.17)$ & $0.94(0.81,0.99)$ & $77.6 \%$ \\
\hline & & & High & $0.42-1.00$ & $0.94(0.11)$ & $1.00(0.95,1.00)$ & $92.0 \%$ \\
\hline & & & Sum & $0.35-1.00$ & $0.96(0.11)$ & $1.00(1.00,1.00)$ & $92.9 \%$ \\
\hline & & & Mean & $0.31-1.00$ & $0.91(0.13)$ & $0.96(0.87,0.99)$ & $86.4 \%$ \\
\hline & & PDC & & $0.19-1.00$ & $0.91(0.17)$ & $0.99(0.92,0.99)$ & $86.5 \%$ \\
\hline \multirow{18}{*}{$\begin{array}{l}\text { Charlson } \\
\text { comorbidities }\end{array}$} & \multirow[t]{9}{*}{0 or 1 comorbidities } & \multirow[t]{4}{*}{ MPRi } & Low & $0.01-1.00$ & $0.46(0.32)$ & $0.41(0.16,0.76)$ & $23.1 \%$ \\
\hline & & & High & $0.15-1.00$ & $0.83(0.21)$ & $0.93(0.74,0.99)$ & $69.1 \%$ \\
\hline & & & Sum & $0.25-1.00$ & $0.95(0.14)$ & $1.00(1.00,1.00)$ & $90.2 \%$ \\
\hline & & & Mean & $0.11-1.00$ & $0.65(0.23)$ & $0.63(0.48,0.87)$ & $32.3 \%$ \\
\hline & & \multirow[t]{4}{*}{ MPRp } & Low & $0.05-1.00$ & $0.83(0.21)$ & $0.92(0.77,0.99)$ & $71.1 \%$ \\
\hline & & & High & $0.10-1.00$ & $0.94(0.13)$ & $1.00(0.94,1.00)$ & $89.5 \%$ \\
\hline & & & Sum & $0.16-1.00$ & $0.96(0.12)$ & $1.00(1.00,1.00)$ & $92.7 \%$ \\
\hline & & & Mean & $0.10-1.00$ & $0.89(0.16)$ & $0.95(0.84,0.99)$ & $80.5 \%$ \\
\hline & & PDC & & $0.15-1.00$ & $0.90(0.18)$ & $0.98(0.90,1.00)$ & $83.1 \%$ \\
\hline & \multirow[t]{9}{*}{$2+$ comorbidities } & \multirow[t]{4}{*}{ MPRi } & Low & $0.05-1.00$ & $0.54(0.34)$ & $0.57(0.16,0.85)$ & $33.3 \%$ \\
\hline & & & High & $0.25-1.00$ & $0.86(0.19)$ & $0.96(0.80,1.00)$ & $74.7 \%$ \\
\hline & & & Sum & $0.41-1.00$ & $0.97(0.10)$ & $1.00(1.00,1.00)$ & $93.3 \%$ \\
\hline & & & Mean & $0.11-1.00$ & $0.71(0.24)$ & $0.76(0.51,0.92)$ & $46.7 \%$ \\
\hline & & \multirow[t]{4}{*}{ MPRp } & Low & $0.08-1.00$ & $0.85(0.19)$ & $0.93(0.75,0.99)$ & $72.0 \%$ \\
\hline & & & High & $0.48-1.00$ & $0.94(0.12)$ & $1.00(0.96,1.00)$ & $89.3 \%$ \\
\hline & & & Sum & $0.53-1.00$ & $0.97(0.09)$ & $1.00(1.00,1.00)$ & $92.0 \%$ \\
\hline & & & Mean & $0.36-1.00$ & $0.90(0.13)$ & $0.95(0.85,0.99)$ & $85.3 \%$ \\
\hline & & \multicolumn{2}{|l|}{ PDC } & $0.25-1.00$ & $0.91(0.15)$ & $0.99(0.88,1.00)$ & $82.7 \%$ \\
\hline
\end{tabular}

Abbreviations: $S D$ standard deviation, IQR interquartile range, MPRi interval based medication possession ratio, MPRp prescription based medication possession ratio, PDC proportion of days covered

and corresponding calculations are inconsistent across studies [7], we note that adherence measure terms alone are inadequate in describing the differences in calculations.

Adjusted logistic regression revealed that regardless of the operational definition used for medication adherence, there was a non-statistically significant trend between adherence to anti-hypertensive medications and lower risk of death. The strength of association was greater in prescription-based measures compared with interval-based measures. However, both methods are not without their faults. While prescription-based measures likely overestimate adherence by not accounting for patients who inappropriately discontinue 
Table 6 Adjusted logistic regression modeling the odds ratio of death, for patients who are adherent versus non-adherent to anti-hypertensive medication

\begin{tabular}{|c|c|c|c|c|c|}
\hline & & & Adjusted $\mathrm{OR}^{\mathrm{b}}$ & $95 \% \mathrm{Cl}$ & $P$ value \\
\hline \multirow[t]{9}{*}{ Overall } & \multirow[t]{4}{*}{ MPRi } & Low & 0.96 & $(0.74,1.23)$ & 0.743 \\
\hline & & High & 0.90 & $(0.68,1.19)$ & 0.475 \\
\hline & & Sum & 0.78 & $(0.58,1.05)$ & 0.104 \\
\hline & & Mean & 0.88 & $(0.68,1.13)$ & 0.321 \\
\hline & \multirow[t]{4}{*}{ MPRp } & Low & 0.79 & $(0.59,1.05)$ & 0.098 \\
\hline & & High & 0.76 & $(0.56,1.05)$ & 0.094 \\
\hline & & Sum & 0.70 & $(0.51,0.97)$ & 0.029 \\
\hline & & Mean & 0.71 & $(0.53,0.95)$ & 0.021 \\
\hline & PDC & & 0.80 & $(0.60,1.07)$ & 0.130 \\
\hline \multirow[t]{3}{*}{ Monotherapy } & MPRi & & 0.80 & $(0.40,1.57)$ & 0.510 \\
\hline & MPRp & & 0.74 & $(0.33,1.66)$ & 0.461 \\
\hline & PDC & & 0.80 & $(0.40,1.57)$ & 0.510 \\
\hline \multirow[t]{9}{*}{ Polytherapy } & \multirow[t]{4}{*}{ MPRi } & Low & 1.06 & $(0.64,1.73)$ & 0.832 \\
\hline & & High & 1.15 & $(0.71,1.85)$ & 0.578 \\
\hline & & Sum & 0.74 & $(0.37,1.49)$ & 0.400 \\
\hline & & Mean & 0.83 & $(0.53,1.31)$ & 0.426 \\
\hline & \multirow[t]{4}{*}{ MPRp } & Low & 0.84 & $(0.53,1.33)$ & 0.455 \\
\hline & & High & 0.99 & $(0.50,1.97)$ & 0.975 \\
\hline & & Sum & 0.65 & $(0.31,1.36)$ & 0.251 \\
\hline & & Mean & 0.66 & $(0.40,1.10)$ & 0.112 \\
\hline & PDC & & 0.80 & $(0.46,1.38)$ & 0.424 \\
\hline
\end{tabular}

${ }^{\mathrm{b}}$ Adjusted for age, sex, Charlson comorbidity index, income quintile, and previous hospitalization for cardiovascular disease

Where "Low" = adherence estimate for the single medication class with the lowest adherence; "High" = adherence estimate for the single medication class with the highest adherence; "Sum" = adherence to any medication class (where days supply for each medication class summed as the numerator); "Mean" = mean adherence to each medication class

Abbreviations: $O R$ odds ratio, $\mathrm{Cl}$ confidence interval, MPRi interval based medication possession ratio, MPRp prescription based medication possession ratio, $P D C$ proportion of days covered

their medications [22], interval-based measures likely underestimate adherence, by interpreting medication switches as non-adherence.

Our sensitivity analysis revealed that the operational definitions that demonstrate the strongest and most significant associations between adherence and mortality vary depending upon the adherence threshold used. When using low MPRp, adherence above the threshold of 0.70 is significantly associated with lower risk of mortality; this significance is lost when higher thresholds are used. For mean MPRp measures, adherence using the thresholds of 0.70 to 0.80 is associated with reduced risk of death, but not when using higher thresholds of 0.85 or 0.90 . For sum MPRp, adherence above the threshold of 0.80 and 0.85 is associated with reduced risk of death.
Therefore, the optimal adherence threshold may differ based on the method used to handle polytherapy. When using stringent measures of adherence (such as when adherence is measured based on the medication with lowest adherence in the case of low MPRp), a lower adherence threshold such as 0.70 may be preferred. In contrast, when using a more liberal measure of adherence (such as considering a patient adherent even if he or she adheres to only one of numerous medications, such as in the case of sum MPRp), a higher adherence threshold such as 0.80 or 0.85 may be preferred.

For the standard adherence threshold of 0.80 , the adherence-mortality association reached statistical significance only when using mean and sum prescription-based MPR measures. These measures likely reflect "overall" adherence to a patient's full regimen of anti-hypertensive medications. Being adherent to only one medication and non-adherent to others (that is, taking into account only highest MPR) is not significantly associated with reduced risk of death, as it may not reflect global adherence to all medications. In contrast, adherence based on "low MPR" (that is, all medication classes must have adherence $\geq 0.80$ ) is likely too stringent a criterion, and its high specificity would result in many patients being considered non-adherent. The mean and sum MPRp are likely a balance between these two extremes, where non-adherence to at least one medication class in a regimen can profoundly affect these adherence estimates. Our study suggests that mean and sum MPRp are the preferred operational measures of adherence, when using the adherence threshold of 0.80, given their significant association with mortality.

Certain limitations in our study deserve consideration. First, to allow calculation of medication adherence over a one-year observation period, we excluded patients who died or did not have at least one prescription refill within one year of their first prescription fill. We have therefore likely excluded those who are sickest and most dependent on chronic medication therapy, and those who are most non-adherent. As a result, adherence is likely overestimated and the association between adherence and mortality weakened. Second, a maximum of five years of follow-up may be insufficiently long to assess association between adherence and mortality. This concern is supported by Kaplan Meier survival curves showing divergence for the non-adherent and adherent groups beginning only at 3.5 to 4 years from index date of diagnosis. Third, it is possible that the older age of the sample population could have confounded the association between medication adherence and mortality. A Cochrane systematic review showed that in the elderly 
aged 80 years or older, anti-hypertensive therapy did not reduce total mortality, though it did reduce cardiovascular mortality and morbidity [23]. Because $25 \%$ of our sample population is aged 80 years or older, in whom there may not be mortality benefit of anti-hypertensive therapy, the overall associations between antihypertensive adherence and mortality may have been weakened by this subgroup. Fourth, because we did not directly compare the different operational definitions of adherence, we cannot state the superiority of one definition over another and therefore cannot recommend a single standardized operational definition for adherence. Rather, our findings suggest that different operational definitions of adherence result in very different estimates of adherence, and certain definitions are associated with long-term outcomes in patients with hypertension, while others are not. Lastly, we used adherence thresholds of 0.80 and a one-year observation period due to its wide usage throughout the literature, despite limited evidence to support these parameters. However, our sensitivity analysis shows similar results and conclusions when using varying adherence thresholds. We recommend confirmation of our findings in a separate large cohort of patients with hypertension, to ensure the validity and generalizability of our conclusions.

\section{Conclusion}

This study is an important contribution to the literature, by providing a better understanding of commonly used medication adherence definitions and their association with outcomes. We recommend the use of prescription-based denominators when calculating medication possession ratios and related measures given their narrower range of estimates and stronger associations with long-term outcomes. In patients using concurrent medications, we recommend using the methods of handling polytherapy that are most strongly associated with mortality. For a standard adherence threshold of 0.80 , these include the mean medication possession ratio (measured as an average of individual class-specific MPRs) and "sum" medication possession ratio (measured as adherence to any medications in the relevant medication classes). We have shown clearly that different operational definitions of medication adherence and different methods of handling polytherapy can result in a wide range of adherence estimates and therefore conclusions reached about adherence, highlighting the need to harmonize these definitions. Given these implications, it is of utmost importance that future adherence studies using pharmacy claims data carefully select and describe the medication adherence definitions used, especially for patients using multiple concurrent medications.

\section{Appendix 1}

Table 7 Antihypertensive medication classes

\begin{tabular}{|c|c|}
\hline Medication Class & Medication Name \\
\hline Thiazide-like Diuretic & $\begin{array}{l}\text { Bendroflumethiazide } \\
\text { Chlorthalidone } \\
\text { Hydrochlorothiazide } \\
\text { Indapamide } \\
\text { Metolazone }\end{array}$ \\
\hline $\begin{array}{l}\text { Angiotensin Converting Enzyme } \\
\text { Inhibitors } \\
\text { or } \\
\text { Angiotensin Receptor Blockers }\end{array}$ & $\begin{array}{l}\text { Benazepril } \\
\text { Captopril } \\
\text { Cilazapril } \\
\text { Enalapril } \\
\text { Fosinopril } \\
\text { Lisinopril } \\
\text { Perindopril } \\
\text { Quinapril } \\
\text { Ramipril } \\
\text { Trandolapril } \\
\text { Candesartan } \\
\text { Eprosartan } \\
\text { Irbesartan } \\
\text { Losartan } \\
\text { Telmisartan } \\
\text { Valsartan }\end{array}$ \\
\hline Beta Blockers & $\begin{array}{l}\text { Acebutolol } \\
\text { Atenolol } \\
\text { Bisoprolol } \\
\text { Labetalol } \\
\text { Metoprolol } \\
\text { Nadolol } \\
\text { Oxprenolol } \\
\text { Pindolol } \\
\text { Propranolol } \\
\text { Timolol }\end{array}$ \\
\hline Calcium Channel Blockers & $\begin{array}{l}\text { Amlodipine } \\
\text { Diltiazem } \\
\text { Felodipine } \\
\text { Nicardipine } \\
\text { Nifedipine } \\
\text { Verapamil }\end{array}$ \\
\hline $\begin{array}{l}\text { Combination containing at least one of } \\
\text { the above medication classes }\end{array}$ & $\begin{array}{l}\text { Atenolol + Diuretics } \\
\text { Candesartan + Diuretics } \\
\text { Cilazapril + Diuretics } \\
\text { Enalapril + Diuretics } \\
\text { Eprosartan + Diuretics } \\
\text { Hydrochlorothiazide + } \\
\text { Potassium Sparing Agents } \\
\text { Irbesartan + Diuretics } \\
\text { Lisinopril + Diuretics } \\
\text { Losartan + Diuretics } \\
\text { Methyldopa + Diuretics } \\
\text { Nadolol + Diuretics } \\
\text { Perindopril + Diuretics } \\
\text { Pindolol + Diuretics } \\
\text { Propranolol + Diuretics } \\
\text { Quinapril + Diuretics } \\
\text { Reserpine + Diuretics } \\
\text { Telmisartan + Diuretics } \\
\text { Timolol + Diuretics } \\
\text { Valsartan + Diuretics }\end{array}$ \\
\hline
\end{tabular}




\section{Appendix 2}

Table 8 Sensitivity analysis for odds ratios modeling death, for patients who are adherent versus non-adherent to antihypertensive medication, using different thresholds to define adherence

\begin{tabular}{|c|c|c|c|c|c|}
\hline & & & Adjusted $\mathrm{OR}^{\mathrm{a}}$ & $95 \% \mathrm{Cl}$ & $P$ value \\
\hline \multirow[t]{9}{*}{ Adherence $>0.65$} & MPRi & Low & 0.96 & $(0.74,1.26)$ & 0.787 \\
\hline & & High & 0.91 & $(0.65,1.26)$ & 0.560 \\
\hline & & Sum & 0.89 & $(0.62,1.27)$ & 0.509 \\
\hline & & Mean & 0.99 & $(0.75,1.31)$ & 0.940 \\
\hline & MPRp & Low & 0.74 & $(0.52,1.06)$ & 0.101 \\
\hline & & High & 0.81 & $(0.53,1.23)$ & 0.317 \\
\hline & & Sum & 0.80 & $(0.52,1.22)$ & 0.294 \\
\hline & & Mean & 0.78 & $(0.53,1.16)$ & 0.222 \\
\hline & PDC & & 0.84 & $(0.60,1.14)$ & 0.323 \\
\hline \multirow[t]{9}{*}{ Adherence $>0.70$} & MPRi & Low & 0.92 & $(0.71,1.19)$ & 0.514 \\
\hline & & High & 0.87 & $(0.64,1.19)$ & 0.385 \\
\hline & & Sum & 0.78 & $(0.56,1.09)$ & 0.151 \\
\hline & & Mean & 0.88 & $(0.67,1.14)$ & 0.324 \\
\hline & MPRp & Low & 0.71 & $(0.51,0.98)$ & 0.036 \\
\hline & & High & 0.71 & $(0.49,1.02)$ & 0.063 \\
\hline & & Sum & 0.69 & $(0.48,1.00)$ & 0.052 \\
\hline & & Mean & 0.64 & $(0.45,0.90)$ & 0.011 \\
\hline & PDC & & 0.77 & $(0.56,1.07)$ & 0.117 \\
\hline \multirow[t]{9}{*}{ Adherence $>0.75$} & MPRi & Low & 0.96 & $(0.75,1.24)$ & 0.767 \\
\hline & & High & 0.91 & $(0.68,1.21)$ & 0.515 \\
\hline & & Sum & 0.81 & $(0.59,1.11)$ & 0.186 \\
\hline & & Mean & 0.88 & $(0.68,1.14)$ & 0.322 \\
\hline & MPRp & Low & 0.74 & $(0.55,1.00)$ & 0.053 \\
\hline & & High & 0.77 & $(0.54,1.08)$ & 0.132 \\
\hline & & Sum & 0.71 & $(0.50,1.00)$ & 0.052 \\
\hline & & Mean & 0.70 & $(0.51,0.97)$ & 0.030 \\
\hline & PDC & & 0.82 & $(0.61,1.11)$ & 0.203 \\
\hline \multirow[t]{9}{*}{ Adherence $>0.80$} & MPRi & Low & 0.96 & $(0.74,1.23)$ & 0.743 \\
\hline & & High & 0.90 & $(0.68,1.19)$ & 0.475 \\
\hline & & Sum & 0.78 & $(0.58,1.05)$ & 0.104 \\
\hline & & Mean & 0.88 & $(0.68,1.13)$ & 0.321 \\
\hline & MPRp & Low & 0.79 & $(0.59,1.05)$ & 0.098 \\
\hline & & High & 0.76 & $(0.56,1.05)$ & 0.094 \\
\hline & & Sum & 0.70 & $(0.51,0.97)$ & 0.029 \\
\hline & & Mean & 0.71 & $(0.53,0.95)$ & 0.021 \\
\hline & PDC & & 0.80 & $(0.60,1.07)$ & 0.130 \\
\hline \multirow[t]{3}{*}{ Adherence $>0.85$} & MPRi & Low & 0.89 & $(0.69,1.15)$ & 0.367 \\
\hline & & High & 0.83 & $(0.64,1.08)$ & 0.175 \\
\hline & & Sum & 0.75 & $(0.57,0.99)$ & 0.044 \\
\hline
\end{tabular}

Table 8 Sensitivity analysis for odds ratios modeling death, for patients who are adherent versus non-adherent to antihypertensive medication, using different thresholds to define adherence (Continued)

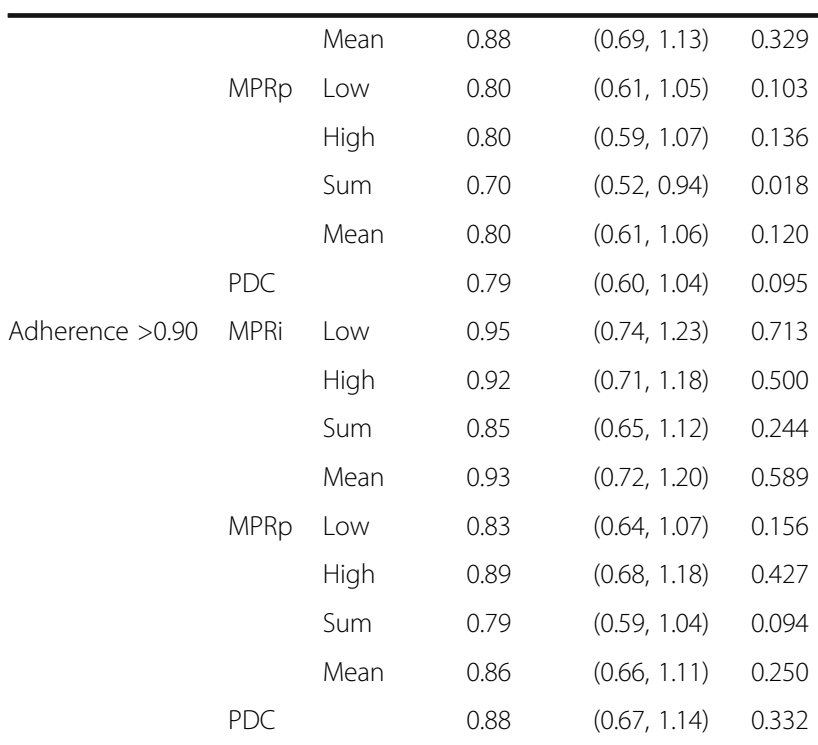

${ }^{a}$ Adjusted for age, sex, Charlson comorbidity index, income quintile, and previous hospitalization for cardiovascular disease

Where "Low" = adherence estimate for the single medication class with the lowest adherence; "High" = adherence estimate for the single medication class with the highest adherence; "Sum" = adherence to any medication class (where days supply for each medication class summed as the numerator); "Mean" = mean adherence to each medication class

Abbreviations: $O R$ odds ratio, $\mathrm{Cl}$ confidence interval, MPRi interval based medication possession ratio, MPRp prescription based medication possession ratio, $P D C$ proportion of days covered

\section{Abbreviations}

ACEl: Angiotensin converting enzyme inhibitor; aOR: Adjusted odds ratio; ARB: Angiotensin receptor blocker; BB: Beta blocker; CCB: Calcium channel blocker; Cl: Confidence interval; ICD-10: International Classification of Diseases, Tenth Revision; ICD-9: International Classification of Diseases, Ninth Revision; MPR: Medication possession ratio; MPRi: Interval based medication possession ratio; MPRp: Prescription based medication possession ratio; OR: Odds ratio; PDC: Proportion of days covered

\section{Acknowledgements \\ None.}

\section{Funding}

This project was funded by Canadian Institutes of Health Research (grant number: MOP-97823). The researchers had independence from the funding agency.

Availability of data and materials

The datasets generated and analyzed during the current study are not publicly available for data privacy and ethical considerations, but are available from the corresponding author upon reasonable request.

\section{Authors' contributions}

Each of the three authors meets the authorship requirements as established by the International Committee of Medical Journal Editors in the Uniform Requirements for Manuscripts Submitted to Biomedical Journals. KT, HQ, and DR conceived of the study. KT performed the statistical analyses, and all authors interpreted this analysis. KT drafted the manuscript, and all performed critical revision of the manuscript. All authors have read and approved the manuscript. 


\section{Competing interests}

K.T. is supported by fellowship awards from the Canadian Institutes of Health Research and Alberta Innovates- Health Solutions, H.Q. receives salary support from Alberta Innovates-Health Solutions, and D.R. is supported by the Population Health Investigator award from Alberta Innovates- Health Solutions. This study is based in part on de-identified data provided by Canadian provincial health ministries and do not represent the views of the provincial governments. The results and conclusions are those of the authors and no official endorsement by Manitoba Health is intended nor should be inferred.

\section{Consent for publication}

Not applicable.

\section{Ethics approval and consent to participate}

Institutional ethics board approval was obtained from the University of Calgary Conjoint Health Research Ethics Board (E18889). Manitoba Health granted access to the administrative databases used in this study. Direct patient consent was not obtained, as the data being analyzed were routinely collected administrative health data that had been de-identified prior to receipt of data.

\section{Author details}

${ }^{1}$ Department of Medicine, University of Calgary, 3330 Hospital Drive NW, T2N 4N1 Calgary, Alberta, Canada. ${ }^{2}$ Department of Community Health Sciences, University of Calgary, 3280 Hospital Drive NW, T2N 4 Z6 Calgary, Alberta Canada.

\section{Received: 27 October 2015 Accepted: 7 February 2017}

\section{Published online: 13 February 2017}

\section{References}

1. Andrade SE, Kahler KH, Frech F, Chan KA. Methods for evaluation of medication adherence and persistence using automated databases. Pharmacoepidemiol Drug Saf. 2006;15(8):565-74. discussion 575-567.

2. Cramer JA, Roy A, Burrell A, et al. Medication compliance and persistence: terminology and definitions. Value Health. 2008;11(1):44-7.

3. Dunbar-Jacob J, Mortimer-Stephens MK. Treatment adherence in chronic disease. J Clin Epidemiol. 2001;54 Suppl 1:S57-60.

4. Sokol MC, McGuigan KA, Verbrugge RR, Epstein RS. Impact of medication adherence on hospitalization risk and healthcare cost. Med Care. 2005:43(6): 521-30.

5. Osterberg L, Blaschke T. Adherence to medication. N Engl J Med. 2005; 353(5):487-97.

6. Cramer JA, Benedict A, Muszbek N, Keskinaslan A, Khan ZM. The significance of compliance and persistence in the treatment of diabetes, hypertension and dyslipidaemia: a review. Int J Clin Pract. 2008;62(1):76-87.

7. Sattler EL, Lee JS. Perri M, 3rd. Medication (re)fill adherence measures derived from pharmacy claims data in older Americans: a review of the literature. Drugs Aging. 2013;30(6):383-99.

8. Choudhry NK, Shrank WH, Levin RL, et al. Measuring concurrent adherence to multiple related medications. Am J Manag Care. 2009;15(7):457-64.

9. Martin BC, Wiley-Exley EK, Richards S, Domino ME, Carey TS, Sleath BL. Contrasting measures of adherence with simple drug use, medication switching, and therapeutic duplication. Ann Pharmacother. 2009;43(1):36-44

10. Health Canada. Federal Public Drug Benefit Programs. October 1, 2004; http://www.hc-sc.gc.ca/hcs-sss/pharma/acces/fedprog-eng.php. Accessed 82014

11. Quan H, Khan N, Hemmelgarn BR, et al. Validation of a case definition to define hypertension using administrative data. Hypertension. 2009:54(6): 1423-8.

12. Robitaille C, Dai S, Waters C, et al. Diagnosed hypertension in Canada: incidence, prevalence and associated mortality. Can Med Assoc J. 2012; 184(1):E49-56

13. Shin $\mathrm{S}$, Song $\mathrm{H}$, Oh SK, Choi KE, Kim H, Jang $\mathrm{S}$. Effect of antihypertensive medication adherence on hospitalization for cardiovascular disease and mortality in hypertensive patients. Hypertens Res. 2013:36(11):1000-5.

14. Lau DT, Nau DP. Oral antihyperglycemic medication nonadherence and subsequent hospitalization among individuals with type 2 diabetes. Diabetes Care. 2004;27(9):2149-53.
15. Rolnick SJ, Pawloski PA, Hedblom BD, Asche SE, Bruzek RJ. Patient characteristics associated with medication adherence. Clin Med Res. 2013, 11(2):54-65.

16. Yang W, Chang J, Kahler KH, et al. Evaluation of compliance and health care utilization in patients treated with single pill vs. free combination antihypertensives. Curr Med Res Opin. 2010;26(9):2065-76.

17. Levesque A, Li HZ, Pahal JS. Factors related to patients' adherence to medication and lifestyle change recommendations: Data from Canada. International Journal of Psychological Studies. 2012;4(2):42.

18. Broadbent E, Donkin L, Stroh JC. Illness and treatment perceptions are associated with adherence to medications, diet, and exercise in diabetic patients. Diabetes Care. 2011;34(2):338-40.

19. Aggarwal B, Mosca L. Lifestyle and psychosocial risk factors predict nonadherence to medication. Ann Behav Med. 2010;40(2):228-33.

20. Halava $\mathrm{H}$, Korhonen MJ, Huupponen $\mathrm{R}$, et al. Lifestyle factors as predictors of nonadherence to statin therapy among patients with and without cardiovascular comorbidities. CMAJ. 2014;186(12):E449-456.

21. Kozma CM, Dickson M, Phillips AL, Meletiche DM. Medication possession ratio: implications of using fixed and variable observation periods in assessing adherence with disease-modifying drugs in patients with multiple sclerosis. Patient Prefer Adherence. 2013;7:509-16.

22. Karve S, Cleves MA, Helm M, Hudson TJ, West DS, Martin BC. An empirical basis for standardizing adherence measures derived from administrative claims data among diabetic patients. Med Care. 2008;46(11):1125-33.

23. Musini VM, Tejani AM, Bassett K, Wright JM. Pharmacotherapy for hypertension in the elderly. Cochrane Database Syst Rev. 2009;4 CD000028.

24. Hansen RA, Voils Cl, Farley JF, et al. Prescriber Continuity and Medication Adherence for Complex Patients. Ann Pharmacother. 2015;49(3):293-302.

25. Krousel-Wood M, Islam T, Webber LS, Re RN, Morisky DE, Muntner P. New medication adherence scale versus pharmacy fill rates in seniors with hypertension. Am J Manag Care. 2009;15(1):59-66.

26. Heisler M, Hogan MM, Hofer TP, Schmittdiel JA, Pladevall M, Kerr EA. When more is not better: treatment intensification among hypertensive patients with poor medication adherence. Circulation. 2008;117(22):2884-92.

27. Baggarly SA, Kemp RJ, Wang X, Magoun AD. Factors associated with medication adherence and persistence of treatment for hypertension in a Medicaid population. Res Social Adm Pharm. 2014;10(6):e99-e112.

28. Bramley TJ, Gerbino PP, Nightengale BS, Frech-Tamas F. Relationship of blood pressure control to adherence with antihypertensive monotherapy in 13 managed care organizations. J Manag Care Pharm. 2006;12(3):239-45.

29. Holmes HM, Luo R, Hanlon JT, Elting LS, Suarez-Almazor M, Goodwin JS. Ethnic disparities in adherence to antihypertensive medications of medicare part D beneficiaries. J Am Geriatr Soc. 2012;60(7):1298-303.

30. Poon I, Lal LS, Ford ME, Braun UK. Racial/ethnic disparities in medication use among veterans with hypertension and dementia: a national cohort study. Ann Pharmacother. 2009:43(2):185-93.

31. Dickson M, Plauschinat CA. Compliance with antihypertensive therapy in the elderly: a comparison of fixed-dose combination amlodipine/benazepril versus component-based free-combination therapy. Am J Cardiovasc Drugs. 2008:8(1):45-50.

32. Krousel-Wood M, Holt E, Joyce C, et al. Differences in cardiovascular disease risk when antihypertensive medication adherence is assessed by pharmacy fill versus self-report: the Cohort Study of Medication Adherence among Older Adults (COSMO). J Hypertens Feb. 2015:33(2):412-20.

33. Stewart K, MC Namara KP, George J. Challenges in measuring medication adherence: experiences from a controlled trial. Int J Clin Pharm. 2014;36(1):15-9

34. Schectman JM, Bovbjerg VE, Voss JD. Predictors of medication-refill adherence in an indigent rural population. Med Care. 2002;40(12):1294-300.

35. Han E, Suh DC, Lee SM, Jang S. The impact of medication adherence on health outcomes for chronic metabolic diseases: A retrospective cohort study. Res Social Adm Pharm. 2014;10(6):e87-98

36. Li P, McElligott S, Bergquist H, Schwartz JS, Doshi JA. Effect of the Medicare Part D coverage gap on medication use among patients with hypertension and hyperlipidemia. Ann Intern Med. 2012;156(11):776-84. W-263, W-264, W265, W-266, W-267, W-268, W-269.

37. Chapman RH, Petrilla AA, Benner JS, Schwartz JS, Tang SS. Predictors of adherence to concomitant antihypertensive and lipid-lowering medications in older adults: a retrospective, cohort study. Drugs Aging. 2008;25(10):885-92. 
38. GuildCare. MedScreen Programs. 2013; https://www.rxscreen.com.au/ ProtocolDocs/MedScreen/GuildCare\%20MedScreen\%20Programs\% 20Protocol.pdf. Accessed 9 Feb 2017.

39. Jackson 2nd KC, Sheng X, Nelson RE, Keskinaslan A, Brixner DI. Adherence with multiple-combination antihypertensive pharmacotherapies in a US managed care database. Clin Ther. 2008;30(8):1558-63.

40. Elliott WJ, Plauschinat CA, Skrepnek GH, Gause D. Persistence, adherence, and risk of discontinuation associated with commonly prescribed antihypertensive drug monotherapies. J Am Board Fam Med. 2007;20(1):72-80.

Submit your next manuscript to BioMed Central and we will help you at every step:

- We accept pre-submission inquiries

- Our selector tool helps you to find the most relevant journal

- We provide round the clock customer support

- Convenient online submission

- Thorough peer review

- Inclusion in PubMed and all major indexing services

- Maximum visibility for your research

Submit your manuscript at www.biomedcentral.com/submit
Biomed Central 